\title{
Large spontaneous HBV DNA fluctuations and potential usefulness of a single point measurement of combined HBV DNA and quantitative HBsAg for the exclusion of HBeAg negative chronic hepatitis B: A prospective Tunisian cohort study
}

\section{Amel Chtourou}

Université de Sfax Faculté de Médecine de Sfax: Universite de Sfax Faculte de Medecine de Sfax

\section{Saba Gargouri}

Université de Sfax Faculté de Médecine de Sfax: Universite de Sfax Faculte de Medecine de Sfax

\section{Emna Elleuch}

Université de Sfax Faculté de Médecine de Sfax: Universite de Sfax Faculte de Medecine de Sfax

\section{Lamia Fki-Berrajah}

Université de Sfax Faculté de Médecine de Sfax: Universite de Sfax Faculte de Medecine de Sfax

\section{Fahmi Smaoui}

University of Sfax Faculty of Medecine of Sfax: Universite de Sfax Faculte de Medecine de Sfax

\section{Awatef Taktak}

Université de Sfax Faculté de Médecine de Sfax: Universite de Sfax Faculte de Medecine de Sfax Khouloud Mnif

Université de Sfax Faculté de Médecine de Sfax: Universite de Sfax Faculte de Medecine de Sfax

\section{Mondher Kassis}

Université de Sfax Faculté de Médecine de Sfax: Universite de Sfax Faculte de Medecine de Sfax

Adnene Hammami

Université de Sfax Faculté de Médecine de Sfax: Universite de Sfax Faculte de Medecine de Sfax

\section{Mounir Ben Jemaa}

Université de Sfax Faculté de Médecine de Sfax: Universite de Sfax Faculte de Medecine de Sfax

HELA KARRAY ( $\nabla$ hela_hakim@yahoo.fr)

Université de Sfax Faculté de Médecine de Sfax: Universite de Sfax Faculte de Medecine de Sfax https://orcid.org/0000-0001-8029-7761

\section{Research Article}

Keywords: 
Posted Date: February 3rd, 2022

DOI: https://doi.org/10.21203/rs.3.rs-1173592/v3

License: (c) (i) This work is licensed under a Creative Commons Attribution 4.0 International License. Read Full License 


\section{Abstract}

Background/Aims: We aimed to describe spontaneous short-term hepatitis B Virus (HBV) DNA level fluctuations and to assess the usefulness of quantitative HBsAg (qHBsAg) in Tunisian patients with HBeAg-negative chronic HBV infection.

Patients and methods: We included 174 treatment-naïve patients with chronic HBeAg-negative HBV. A one-year prospective follow-up was carried out with serial determinations of HBV DNA, alanine aminotransferase levels and qHBsAg. Patients were classified into three groups: inactive carriers (G1), patients with HBeAg negative chronic hepatitis B (CHB) (G2) and patients with "indeterminate state" (G3). For this latter group, a liver biopsy was indicated.

Results: Only genotype D was detected. During the follow-up, $21.6 \%$ and $19.5 \%$ of patients with low initial ( $<2000 \mathrm{IU} / \mathrm{mL}$ ) and intermediate viral load $(2000-20000 \mathrm{IU} / \mathrm{mL})$, experienced a subsequent increase in their HBV DNA levels above 2000 and $20000 \mathrm{lU} / \mathrm{mL}$, respectively. Significant variations of HBV DNA levels $(\geq 0.5 \log 10 \mathrm{IU} / \mathrm{mL}$ ) were observed in $61.1 \%$ of patients at 6 months-interval. Among the 174 patients, 89 (51.1\%) belonged to $\mathrm{G} 1,33(19 \%)$ to $\mathrm{G} 2$ and $52(29.9 \%)$ to G3. Fourteen patients have undergone liver biopsy, among whom 7 (50\%) showed moderate to severe liver disease. Combination of HBV DNA $<2000$ $\mathrm{IU} / \mathrm{mL}$ and $\mathrm{qHBsAg}<832 \mathrm{IU} / \mathrm{mL}$ excluded $\mathrm{CHB}$ in $98.4 \%$ of cases.

Conclusions: This study highlights the large short-term HBV DNA fluctuations in Tunisian patients with HBeAg negative chronic HBV of genotype D. HBV DNA $<2000 \mathrm{IU} / \mathrm{mL}$ along with $\mathrm{qHBsAg}<832 \mathrm{IU} / \mathrm{mL}$ excluded CHB in $98.4 \%$ of cases. Significant proportion of patients with "indeterminate state" within genotype D would have HBeAg negative CHB.

\section{Background}

Chronic hepatitis B (CHB) is a major cause of liver disease worldwide. HBV infection is still endemic in Tunisia. However, a gradual shift from high to intermediate-low endemicity is currently observed mainly due to the implementation of the vaccination program since 1995. Indeed, according to a recent national survey on viral hepatitis seroprevalence in the years 2014-2015 [1], hepatitis B surface antigen (HBsAg) carriage rate was $1.8 \%$, confirming the significant decrease in HBV infection seroprevalence, which was $6.5 \%$ in the $1990 \mathrm{~s}$ [2].

During the natural course of hepatitis $\mathrm{B}$ e antigen (HBeAg)-negative $\mathrm{CHB}$, fluctuations in both HBV DNA (viral load) and ALT (alanine aminotransferase) levels are often observed, making patient's classification very difficult. Although significant variations in HBV DNA levels have been well documented during this phase, a little is known about short-term HBV DNA fluctuations. Thus, serial determinations of these two parameters (HBV DNA and ALT levels) for a period of at least one year are mandatory to avoid misclassification of infected patients [3]. Recently, several studies have suggested the potential role of HBsAg quantification (qHBsAg), in addition to HBV DNA levels for a reliable and accurate determination of the actual HBV infection phase [4-6]. 
The aim of this study was to describe spontaneous HBV DNA fluctuations and to assess the usefulness of qHBsAg in HBV infection diagnosis over a one year prospective follow-up period among Tunisian patients with HBeAg-negative chronic HBV infection.

\section{Patients And Methods}

\section{Study population and prospective follow-up}

Patients with chronic HBV infection were consecutively enrolled by the Department of Infectious Diseases, Hedi Chaker University Hospital and the Laboratory of Microbiology, Habib Bourguiba University Hospital, Sfax, Tunisia, from January 2014 to April 2016. Inclusion criteria were: untreated patients above 18 years old, asymptomatic, positive for HBsAg for at least 6 months, negative for anti $\mathrm{HBC} \operatorname{lgM}$ and $\mathrm{HBeAg}$ and positive for anti-HBe. Exclusion criteria were: patients with hepatitis $\mathrm{C}$ virus $(\mathrm{HCV})$, hepatitis D virus (HDV), Human immunodeficiency virus (HIV) co-infection or other causes of chronic hepatopathy (alcoholic or autoimmune disease), pregnant women and patient receiving immunosuppressive therapy. Overall, 217 patients were initially recruited and prospectively followed-up every three months (M) over a period of one year (M0, M3, M6, M9 and M12). During the follow-up, 43 patients were secondarily excluded because of unavailable serum sample in 30 cases, anti-viral therapy indication in 6 cases and pregnancy in 7 cases. Thus, 174 patients were finally included in the study. All patients gave written and informed consent to participate in the study, which was approved by the ethical committee of Habib Bourguiba University Hospital.

At inclusion (M0), demographic characteristics (age, gender), liver function test: ALT, aspartate aminotransferase (AST), abdominal ultrasound and virological markers (HBV DNA and qHBsAg) were performed for all patients. During follow up, serial determinations for both HBV DNA and ALT levels were obtained at three times with an interval of 6 months (M0, M6 and M12) at five times with an interval of 3 months (M0, M3, M6, M9 and M12), respectively. Quantification of HBsAg was performed in M0 and M12 for all carriers.

\section{Laboratory methods}

Liver biochemistries were performed in commercially available multiparametric automated analyzer (DxC $600 \AA$ (Beckman Coulterlnc, Brea, CA, USA). According to this method, the upper limit of normal (ULN) ALT values was $50 \mathrm{IU} / \mathrm{L}$. Abnormal ALT levels were considered if at least two ALT determinations were > ULN throughout the follow-up.

Qualitative HBsAg and $\mathrm{HBeAg} /$ anti-HBe determinations were performed by electrochemiluminescent assay (COBAS e411 Analyzer, Roche Diagnostics, Germany). Serum HBV DNA was measured by real-time PCR using the COBAS TaqMan 48 Analyzer/ COBAS TaqMan HBV test (Roche Diagnostics, Germany) with a detection treshold of $6 \mathrm{IU} / \mathrm{mL}$ and a linear range of $29-1.10^{8} \mathrm{IU} / \mathrm{mL}$. 
Determination of HBV genotype was performed by multiplex PCR using type-specific primers allowing the identification of genotypes A through $\mathrm{F}$ [7].

Quantification of HBsAg was performed using the COBAS e411 Analyzer /Elecsys HBsAg II test (Roche Diagnostics, Germany). The 1/100e dilution of the samples allowed the measurement of a value within the range of quantification of $5-13,000 \mathrm{IU} / \mathrm{mL}$. Samples with HBsAg levels $>13,000 \mathrm{IU} / \mathrm{mL}$ were diluted to $1 / 100$ to reach the value within the range of quantification and those $<5 \mathrm{IU} / \mathrm{mL}$ were retested pure. The detection limit of the test is $0.05 \mathrm{IU} / \mathrm{mL}$.

\section{Classification of the patients}

At the end of the one year monitoring, HBV carriers were classified according to their biochemical and virological profiles: patients with persistently low HBV DNA $(<2000 \mathrm{IU} / \mathrm{mL})$ and normal $A L T(<U L N)$, were classified in group 1 (G1) as HBsAg inactive carriers (IC) (patients with HBeAg negative Chronic infection). Patients having at least one high viral load (HBV DNA $\geq 20,000 \mathrm{IU} / \mathrm{mL}$ ) and those with an intermediate viral load (between 2000 and $20,000 \mathrm{IU} / \mathrm{mL}$ ) with persistently or intermittently abnormal ALAT were classified in Group 2 (G2) as HBeAg negative CHB patients. Group 3 (G3) included patients who were not belonging to $\mathrm{G} 1$ nor G2. These patients designated with « indeterminant status » had at least one HBV DNA between 2000 and $20,000 \mathrm{IU} / \mathrm{mL}$ with persistently normal ALT or low viral load $<2000$ $\mathrm{UI} / \mathrm{mL}$ with persistently or intermittently abnormal ALAT. For these patients, a liver biopsy was recommended. Patients who had undergone a liver biopsy showing a Metavir histologic score above A2 and/or F2, were secondarily classified in G2.

\section{Statistical analysis}

The logarithmic transformation was used for quantitative data without normal distribution such as HBV DNA and qHBsAg in order to evaluate its variations over time. Data were analyzed using SPSS version 20. Continuous variables were expressed as medians (ranges) and categorical variables were expressed as percentages. Differences between subgroups were analyzed using Mann-Whitney and Kruskall Wallis non-parametric test when appropriate. A $p$ value of $\leq 0.05$ was considered to denote of statistical significance.

For each patient, the largest difference in HBV DNA levels between two consecutive visits (M0-M6, M6M12) was recorded: a HBV DNA fluctuation $\geq 0.5 \log _{10} \mathrm{IU} / \mathrm{mL}$ was considered as significant. Similarly, qHBsAg fluctuation $\geq 0.5 \log _{10} \mathrm{IU} / \mathrm{mL}$ between $\mathrm{M} 0$ and $\mathrm{M} 12$ was considered as significant.

The diagnostic performance of qHBsAg was evaluated by receiver operating characteristic (ROC) curve. The cut-off value to discriminate chronic hepatitis patients from inactive carriers was selected considering the highest sensitivity + specificity sum. Only G1 and G2 patients were included in the analysis, as having a well-defined status at the end of follow-up.

\section{Results}




\section{Baseline patient characteristics}

Median age of included patients was 35 years (range: $21-66)$. The sex ratio was 6.56 (151/23). Serial ALT and AST determinations at MO were 0.52 (0.24-1.88) and 0.62 (0.38-1.98) the ULN, respectively. The median $\log _{10} \mathrm{HBsAg}$ titer and HBV DNA levels at baseline were respectively $2.93(-0.71-4.8)$ and 2.63 (not detected-6.23) IU/mL. Signs of chronic hepatopathy shown by abdominal ultrasound were noted in four patients $(2.3 \%)$.

Determination of HBV genotype could be performed for 97 patients. Genotype D was the only found.

\section{HBV DNA fluctuations}

HBV DNA monitoring is shown in Table 1. At M0, 125 (71.8\%), 41 (23.6\%) and $8(4.6 \%)$ of included patients had HBV DNA levels $<2000$, [2000-20,000[ and $\geq 20,000 \mathrm{IU} / \mathrm{mL}$, respectively. Out of 125 patients with low HBV DNA at M0, seven (5.6\%) maintained undetectable viral load throughout the follow-up and 27 (21.6\%) have experienced at least one fluctuation (at M6 and / or M12), ranging between $2000 \mathrm{IU} / \mathrm{mL}$ and 20,000 in 26 cases and reaching more than $20,000 \mathrm{IU} / \mathrm{mL}$ in the remaining case. Among the 41 subjects initially having an intermediate viral load, 8 (19.5\%) had at least one increase in their HBV DNA above 20,000 IU/mL (in M6 and / or M12). Thus, the proportion of patients with HBV DNA $\geq 2000 \mathrm{IU} / \mathrm{mL}$, increased from $28.2 \%$ at M0 (49/174) to $37.3 \%$ at M6 (65/174) and to $43.7 \%$ at M12 (76/174).

For patients with detectable HBV DNA at inclusion $(\mathrm{N}=167)$, the median HBV fluctuation was $0.58 \log _{10}$ $\mathrm{IU} / \mathrm{mL}$ (range: 0.03 to $3.14 \log _{10} \mathrm{IU} / \mathrm{mL}$ ). One hundred and two patients $(61.1 \%$ ) have experienced significant fluctuations of their viral load $\left(\geq 0.5 \log _{10} \mathrm{IU} / \mathrm{mL}\right)$ at 6-month interval. Interestingly, 41 out of the 102 patients (40.2\%) have shown fluctuation over $1 \log _{10} \mathrm{IU} / \mathrm{mL}$.

\section{Patients classification}

At the end of the one year prospective follow-up, 89, 26 and 59 of included patients belonged to G1, G2 and G3, respectively. Liver biopsy was performed for 14 patients of G3, of whom seven patients (50\%) showed a metavir histologic score above A2 and/or F2 and therefore were secondarily classified into G2 (Table 2).

Thus, the population study was finally classified into 89 inactive carriers $(51.1 \%), 33$ patients $(19 \%)$ into G2 and 52 patients (29.9\%) into G3.

Demographic, biological and virological characteristics of the three groups of patients are shown in Table 3. G1 patients were significantly older, had serum ALT, AST, TB and HBV DNA significantly lower than those belonging to $\mathrm{G} 2$ and $\mathrm{G} 3$. In addition, $\mathrm{G} 2$ patients had serum GGT levels significantly higher than those of G1 and G3. No statistically significant difference was observed between the three groups in terms of PAL, PT, leukocytes, hemoglobin and platelets count.

\section{HBsAg quantification and ROC curve analysis}


Medians of qHBsAg determined at M0 and M12 were 2.93 [-0.71 to 4.8] and 2.99 [-1.3 to 4.94] $\log _{10}$ $\mathrm{IU} / \mathrm{mL}$, respectively. Median HBsAg levels $\left(\log _{10} \mathrm{IU} / \mathrm{mL}\right)$ were significantly lower in patients belonging to G1 than those belonging to $\mathrm{G} 2$ and $\mathrm{G} 3$ (table 3).

The diagnostic performance of qHBsAg serum levels was evaluated by ROC curve in order to establish a cut-off value of qHBsAg allowing the identification, at the first visit (M0), of the clinical phase of chronic infection with negative HBeAg (IC or CHB) (Figure 1).

This analysis included two groups of patients $\mathrm{G} 1$ and $\mathrm{G} 2$. The area under the receiver operating characteristic (AUROC) of qHBsAg to identify CHB in the overall cohort was 0.817 (95\% Cl: $0.73-0.9, p$ $<0.0001$ ). The qHBsAg cut off with the highest sensitivity and specificity was $832 \mathrm{IU} / \mathrm{mL}$ (sensitivity: $86.2 \%$, specificity: 68.5 , PPV: $47.2 \%$, NPV: 93.8 ). Thus, a value of $\mathrm{qHBsAg}<832 \mathrm{IU} / \mathrm{mL}$ at M0 allowed us to exclude $\mathrm{CHB}$ in $93.8 \%$ of cases. Interestingly, the combination of the two parameters qAgHBs $<832$ $\mathrm{IU} / \mathrm{mL}$ and HBV DNA levels $<2000 \mathrm{IU} / \mathrm{mL}$ at $\mathrm{MO}$ allowed us to exclude $\mathrm{CHB}$ in $98.4 \%$.

Furthermore, significant qHBsAg fluctuations ( $\geq 0.5 \log _{10} \mathrm{IU} / \mathrm{mL}$ ) were noted in only 15 patients (8.6\%) of whom 11 (73.3\%) belonged to G1. Of note, three patients achieved HBsAg clearance at M12 with anti-HBs seroconversion. Further follow-up could be performed for 66 among the 89 inactive carriers, during a period ranging from 12 to 48 months. Interestingly, HBsAg clearance was observed in 10 additional patients of whom anti-HBs seroconversion was achieved in 4 cases. Therefore, the annual spontaneous HBsAg loss rate among the inactive carriers was estimated to $4.2 \%$. All patients with HBsAg clearance had baseline qHBsAg levels $<100 \mathrm{IU} / \mathrm{mL}$. Annual qHBsAg decline was significantly higher in patients with anti-HBs seroconversion than those without seroconversion $\left(0.91 \log _{10} \mathrm{IU} / \mathrm{mL}\right.$ vs $0.07 \log _{10} \mathrm{IU} / \mathrm{mL}$, respectively, $p=0.001$ ).

\section{Discussion}

In the present study, a prospective follow-up during a one-year period of a cohort of 174 treatment-naïve $\mathrm{HBeAg}$ negative Tunisian patients was performed. Patients monitoring was based on the determination of serum HBV DNA levels every 6 months and ALT levels every 3 months, which allowed the classification of patients at the end of the monitoring. During the follow-up, $21.6 \%$ and $19.5 \%$ of patients with low initial $(<2000 \mathrm{IU} / \mathrm{mL})$ and intermediate viral load $(2000-20000 \mathrm{IU} / \mathrm{mL})$, experienced a subsequent increase in their HBV DNA levels above $2000 \mathrm{IU} / \mathrm{mL}$ and $20000 \mathrm{IU} / \mathrm{mL}$, respectively. These results suggest that a chronically infected HBeAg negative patient has a probability of approximately $20 \%$ to spontaneously switch from one interval to another during the following year. Overall, the proportion of patients with a viral load $>2000 \mathrm{IU} / \mathrm{mL}$ passed from $28.2 \%$ at the initial visit (M0) to $43.7 \%$ at $\mathrm{M} 12$. Furthermore, significant variations of HBV DNA levels $\left(\geq 0.5 \log _{10} \mathrm{lU} / \mathrm{mL}\right.$ ) were observed in $61.1 \%$ of patients at 6 months-interval. Similar results have been reported by Maylin and al, showing that $63 \%$ of Senegalese patients experienced a large viral load fluctuation at 4 months-interval [8]. Altoghether, our findings highlight the volatility and the short-term frequency of HBV DNA fluctuations in treatment-naïve HBeAg negative Tunisian patients infected with HBV of genotype D, suggesting that HBV viral load as a single 
biomarker cannot provide the answer for the actual CHB disease activity, and even a close monitoring of this biomarker may not accurately define the HBV infection phase or help to make decision to treat.

Interestingly, in the present study, nearly $30 \%$ of the cohort population fell into "indeterminant state" (G3) after one year follow-up. Significant differences were found between inactive carriers (G1) and patients with HBeAg negative CHB (G2) or with indeterminant state (G3) in relation to demographic and biological characteristics. Similarly, the level of qHBsAg determined at M0 was significantly lower in (G1) than in (G2) or (G3). These findings suggest that patients belonging to $G 3$ group would be closer to $G 2$ than to G1 group; hence, significant proportion of G3 patients would have HBeAg negative CHB.

Indeed, among 14 patients from G3 who have undergone a liver biopsy, 7 (50\%) showed moderate to severe liver disease, with Metavir score $\geq A 2$ and/or F2. In other reports, however, indeterminant patients with HBV DNA levels of $2000-10000 \mathrm{IU} / \mathrm{mL}$ or $2000-20,000 \mathrm{IU} / \mathrm{mL}$ and persistent normal ALT concentration were more similar to patients with low HBV DNA in relation to clinical, histological, and laboratory characteristics and therefore, it is concluded that they can be clinically managed as HBV inactive carriers $[9,10]$. One reason for the discordant results could be the criteria selected for the definition of patients with "indeterminant state". Another possible explanation is HBV genotype, given that the above mentioned studies included predominantly Asian patients of genotype A, B and C. Indeed, compared to other genotypes, it was concluded that patients with genotypes D, C, and F1 are more likely to develop complications such as liver cirrhosis and HCC [11]. A study from India has suggested that genotype D was associated with more severe liver diseases and HCC in younger patients than genotype A [12]. Another study from China has also shown that genotype $A$ and $B$ patients have a higher rate of HBsAg sero-clearance than genotype $C$ and $D$ patients [13].

The actual state of patients with viral load between $2000-20000 \mathrm{Ul} / \mathrm{mL}$ and normal ALAT or those having low levels of HBV DNA $<2000 \mathrm{UI} / \mathrm{mL}$ with hepatic flares is not well-characterized. These profiles could correspond to inactive carriage, to HBeAg CHB state or even to patients who are likely to subsequently clear HBsAg [14]. Furthermore, it has been recently suggested that for patients with very low level of viremia, an elevation of ALT should prompt investigation into alternate causes such as medications, alcohol and steatosis [10]. In our study, among the 7 patients with abnormal liver biopsy, 4 patients showed fibrosis scores $\geq \mathrm{F} 2$. The initial profile of these patients was viral load between $2000-$ $20000 \mathrm{UI} / \mathrm{mL}$ and normal ALAT in one case and low levels of HBV DNA $<2000 \mathrm{UI} / \mathrm{mL}$ with hepatic flares in the remaining 3 cases. Interestingly, all of them showed low qHBsAg levels at M0 (range: 5.85-898.3 $\mathrm{IU} / \mathrm{ml}$ ). Indeed, it has been previously suggested that qHBsAg levels are negatively correlated with advanced stages of liver fibrosis in treatment-naive African chronic hepatitis B HBeAg-negative patients [15]. Therefore, whether such profiles within genotype $D$, especially those with low levels of HBV DNA, abnormal ALAT levels and low qHBsAg, are really of good prognosis, should be considered with precaution. These profiles stress the need to be more investigated.

Thus, a single HBV DNA determination at a given time can not reflect the true status of patients so a regular and close monitoring is mandatory to optimize their support. However, the determination of HBV 
DNA is very expensive and not routinely available in all laboratories in Tunisia. Several studies have shown that qHBsAg could be of a great relevance in phase definition and prediction of HBsAg seroclearance [16-19]. In the present study, we evaluated the performance of qHBsAg serum levels by ROC curve to define, at the first visit (M0), the actual phase of HBeAg negative chronic infection (IC or $\mathrm{CHB}$ ). A qHBsAg serum level of $<832 \mathrm{UI} / \mathrm{mL}$ allowed the exclusion of HBeAg CHB state in $93.8 \%$ of cases. Interestingly, the most accurate diagnostic approach was achieved by combining qHBsAg $<832$ $\mathrm{IU} / \mathrm{mL}$ and HBV DNA $<2000 \mathrm{IU} / \mathrm{mL}$, which excludes CHB in $98.4 \%$ of cases. Similar results were reported by Oliveri and al [20] showing that combined single point HBV DNA $\leq 2000 \mathrm{IU} / \mathrm{mL} / \mathrm{HBsAg} \leq 1000 \mathrm{IU} / \mathrm{mL}$ allowed the exclusion of CHB with NPV of $100 \%$. The potential reason for the slight difference in qHBsAg cut-off, compared to several studies which suggested a cut-off of $1000 \mathrm{IU} / \mathrm{mL}$, could be that our group of HBeAg negative CHB patients (G2) was more heterogenous, including patients with both activity and advanced fibrosis scores, hence the presence of low qHBsAg levels in this group of patients, as it was mentioned above.

In our cohort, significant qHBsAg fluctuations $\geq 0.5 \log _{10} \mathrm{lU} / \mathrm{mL}$ were observed in $8.6 \%$ of cases throughout the follow-up. Notably, these fluctuations were primarily found in the inactive carriers group (G1) (73.3\%). These results were consistent with those of Brunetto [4] and Tung Hung Su [21] showing that the most wide qHBsAg fluctuations were observed in inactive carriers, especially in the later stage of disease. Indeed, within this group, 13 patients achieved HBsAg seroclearance. As it was previously reported [22, 23], all these patients showed lower baseline qHBsAg $<100 \mathrm{IU} / \mathrm{mL}$, with specifically an annual decline significantly higher for those who achieved anti-HBs seroconversion. These results highlight the potential relevance of qHBsAg for CHB functional cure prediction.

To our knowledge, this study is the first to assess HBV DNA fluctuations and qHBsAg in a cohort of patients chronically infected with HBV of genotype $D$ in North Africa. Strengths of this study are: first, the classification of patients was based on a regular prospective follow up, through the determination of HBV DNA and ALT levels, and not on a single measurement. Second, our group of patients with HBeAg negative CHB (G2) included those with advanced fibrosis based on liver biopsy which provides a more reliable assessment of qHBsAg for phase diagnosis. Nevertheless, several limitations exist: the low numbers of patients within G3 who have undergone a liver biopsy, and the relatively short period of follow up after the first year.

\section{Conclusion}

In summary, this study highlighted the large spontaneous fluctuations of HBV DNA during HBeAg negative CHB in HBV infected genotype D Tunisian population, and showed that approximately $20 \%$ of patients will spontaneously transit from one HBV DNA interval to another during the following year. A cutoff value of $\mathrm{qHBsAg}<832 \mathrm{IU} / \mathrm{mL}$ associated with $\mathrm{HBV}$ DNA $<2000 \mathrm{IU} / \mathrm{mL}$ allowed the exclusion of HBeAg negative $\mathrm{CHB}$ in $98 . \%$, and a cut-off of $\mathrm{qHBsAg}<100 \mathrm{IU} / \mathrm{mL}$ associated with an annual decline of $>$ $0.5 \log _{10} \mathrm{IU} / \mathrm{mL}$ are good predictors markers of hepatitis $B$ functional cure. Approximately one third of our patients are designated as having an "indeterminant state" during CHB. Low levels of qHBsAg associated 
with low HBV DNA and abnormal ALAT may be predictors of advanced fibrosis in this subgroup, which need to be confirmed by further investigations in a large scale population.

\section{Declarations}

\section{Data availability}

The datasets generated during and/or analyzed during the current study are available from the corresponding author on reasonable request.

\section{Funding}

The authors declare that no funds, grants, or other support were received during the preparation of this manuscript.

\section{Competing Interests}

The authors have no relevant financial or non-financial interests to disclose.

\section{Author Contributions}

Amel Chtourou designed the project, collected and analyzed data, and wrote the article; Saba Gargouri designed the project, interpreted data, and wrote the manuscript ; Emna Elleuch analyzed and interpreted data; Fahmi Smaoui and Awatef Taktak contributed to the revision of the manuscript; Lamia Fki-Berrajah designed the project and revised the manuscript; Khouloud Mnif collected data; Mondher Kassis assisted in statistical analysis of the survey data; Adnene Hammami and Mounir Ben Jemaa gave final approval of the version to be published; Hela Karray criticized the manuscript and gave final approval of the version to be published.

\section{Ethics approval}

The study was conducted according to the guidelines of the Declaration of Helsinki, and was approved by the Ethics Committee of Habib Bourguiba University Hospital (protocol code : 06/15 date of approval : 01 april 2015).

\section{Consent to participate}

Informed consent was obtained from all patients involved in the study.

\section{References}

1. Ben Hadj Boudali M, Hazgui O, Bouguerra H, et al. Hépatite B en Tunisie. Épidémiologie, facteurs de risque et impact de la vaccination. EM Consulte 2019; 67(S3): P.S158. 
2. Triki H, Said N, Ben Salah A, et al. Seroepidemiology of hepatitis B, C and delta viruses in Tunisia. Trans R Soc Trop Med Hyg. 1997;91(1):11-4.

3. Lampertico P, Agarwal K, Berg T, et al. EASL 2017 Clinical Practice Guidelines on the management of hepatitis B virus infection. J Hepatol. 2017;67(2):370-98.

4. Brunetto MR, Oliveri F, Colombatto $P$, et al. Hepatitis $B$ surface antigen serum levels help to distinguish active from inactive hepatitis $B$ virus genotype $D$ carriers. Gastroenterology. 2010;139(2):483-90.

5. Chan HLY, Thompson A, Martinot-Peignoux $M$, et al. Hepatitis B surface antigen quantification: Why and how to use it in 2011 - A core group report. J Hepatol. 2011;55(5):1121-31.

6. Seth AK. HBsAg quantification in clinical practice. J Clin Exp Hepatol. 2012;21(1):75-80.

7. Naito $H$, Hayashi $S$, Abe K. Rapid and specific genotyping system for hepatitis $B$ virus corresponding to six major genotypes by PCR using type-specific primers. J Clin Microbiol. 2001;39(1):362-4.

8. Maylin S, Sire J-M, Mbaye PS, et al. Short-term spontaneous fluctuations of HBV DNA levels in a Senegalese population with chronic hepatitis B. BMC Infect Di. 2015;15(1):1-8.

9. Keshvari M, Alavian SM, Sharafi H. How can we make decision for patients with chronic hepatitis $B$ according to hepatitis B virus (HBV) DNA level? Hepat Mon 2014; 14(2).

10. Zhou K, Abdus S. Wahed AS, Cooper S, et al. Phase transition is infrequent among North american adults with e-antigen negative chronic hepatitis B and low-level viremia. Am J Gastroenterol. 2019;114(11):1753-63.

11. Zhang ZH, Wu CC, Chen XW, Li X, Li J, Lu MJ. Genetic variation of hepatitis B virus and its significance for pathogenesis. World J Gastroenterol. 2016;22(1):126-44.

12. Thakur V, Guptan RC, Kazim SN, Malhotra V, Sarin SK. Profile, spectrum and significance of HBV genotypes in chronic liver disease patients in the Indian subcontinent. J Gastroenterol Hepatol. 2002;17(2):165-70.

13. Yuen MF, Wong DK, Sablon E, et al. HBsAg seroclearance in chronic hepatitis B in the Chinese: virological, histological, and clinical aspects. Hepatology. 2004;39(6):1694-701.

14. Freundlich DI, Samad N, Miles D, et al. Spontaneous flares of chronic hepatitis B virus in hepatitis B e antigen negative carriers who subsequently clear hepatitis B surface antigen. Dig Dis Sci. 2021;66(1):257-62.

15. Fulgence $M$, Bathaix $Y$, Soro $D$, et al. Hepatitis $B$ surface antigen serum level is correlated with fibrosis severity in treatment-naïve, chronic hepatitis B patients in Côte d'Ivoire (West Africa)? Open J Gastroenterol. 2015;8(5):164-72.

16. Ungtrakul T, Sriprayoon T, Kusuman P, et al. Role of quantitative hepatitis B surface antigen in predicting inactive carriers and $\mathrm{HBsAg}$ seroclearance in $\mathrm{HBeAg}$-negative chronic hepatitis $\mathrm{B}$ patients. Medicine (Baltimore) 2017; 96, e6554.

17. Maimone S, Caccamo G, Squadrito G, et al. A combination of different diagnostic tools allows identification of inactive hepatitis B virus carriers at a single time point evaluation. Liver Int. 
2017;37:362-8.

18. Liu J, Yang HI, Lee MH, et al. Serum levels of hepatitis B surface antigen and DNA can predict inactive carriers with low risk of disease progression. Hepatology. 2016;64:381-9.

19. Martinot-Peignoux M, Lapalus M, Laouenan C, et al. Prediction of disease reactivation in asymptomatic hepatitis $B$ e antigen-negative chronic hepatitis $B$ patients using baseline serum measurements of HBsAg and HBV-DNA. J Clin Virol. 2013;58:401-7.

20. Oliveri F, Surace L, Cavallone D, et al. Long-term outcome of inactive and active, low viraemic HBeAgnegative-hepatitis B virus infection: Benign course towards HBsAg clearance. World J Gastroenterol. 2008;14(40):6154-62.

21. Su TH, Liu CJ, Tseng TC, et al. Longitudinal Change of HBsAg in HBeAg-negative Patients with Genotype B or C Infection. PLoS One. 2013;8(2):1-7.

22. Oliveri F, Surace L, Cavallone D, et al. Long-term outcome of inactive and active, low viraemic $\mathrm{HBeAg}$ negative-hepatitis B virus infection: benign course towards HBsAg clearance. Liver Int. 2017;37(11):1622-31.

23. Chan HL, Wong GL, Tse CH, Chan HY, Wong VW. Viral determinants of hepatitis B surface antigen seroclearance in hepatitis B e antigen-negative chronic hepatitis B patients. J Infect Dis. 2011;204:408-14.

\section{Tables}

Table 1.

HBV DNA levels during the one year-follow-up

\begin{tabular}{|llll|}
\hline & M0 & M6 & M12 \\
\hline HBV DNA $\log _{10} \mathrm{IU} / \mathrm{mL}$ & $\mathrm{N}(\%)$ & & \\
\hline$<2000$ & $125(71.8)$ & $109(62.7)$ & $98(56,3)$ \\
\hline 2000- 20 000[ & & & $59(33,9)$ \\
& $41(23,6)$ & $54(31)$ & \\
\hline 20 000 & $8(4,6)$ & $11(6,3)$ & $17(9,8)$ \\
\hline medians/ranges & $2.63[\mathrm{ND}-6.23]$ & $2.73[\mathrm{ND}-7.92]$ & $2.52[\mathrm{ND}-7.77]$ \\
\hline
\end{tabular}

HBV DNA, hepatitis B virus deoxyribonucleic acid; $M$, month; N, number ; ND, not detected

Table 2. 
Features of patients with indeterminate state (G3 group) with Metavir histologic score above A2 and/or F2

\begin{tabular}{|llllll|}
\hline Patient $\mathbf{n}^{\circ}$ & $\begin{array}{l}\text { Age } \\
\text { (Years) }\end{array}$ & Abnormal ALT & $\begin{array}{l}\text { HBV DNA fluctuation } \\
\geq 2000 \mathrm{IU} / \mathrm{mL}\end{array}$ & $\begin{array}{l}\text { qHBsAg at M0 } \\
\text { IU/mL }\end{array}$ & Metavir Score \\
\hline 1 & 34 & No & Yes & 179.6 & A1F2 \\
\hline 2 & 42 & No & Yes & 3023 & A2F1 \\
\hline 3 & 36 & No & Yes & 11270 & A2F1 \\
\hline 4 & 34 & No & Yes & 24220 & A2F2 \\
\hline 5 & 40 & Yes & No & 5.85 & A1F2 \\
\hline 6 & 51 & Yes & No & 50.44 & A3F3 \\
\hline 7 & 31 & Yes & No & 898.3 & A1F2 \\
\hline
\end{tabular}

Group 3 include patients who had at least one HBV DNA measurement between 2000 and 20,000 IU/mL with consistently normal ALT, or low viral load $<2000 \mathrm{UI} / \mathrm{mL}$ with persistently or intermittently abnormal ALT. ALT, alanine aminotransferase; HBV DNA, hepatitis B virus deoxyribonucleic acid; qHBsAg, quantitative hepatitis B surface antigen.

\section{Table 3.}

Demographic and biological Characteristics of patients groups (G1, G2, G3) 


\begin{tabular}{|c|c|c|c|c|}
\hline & Median (ranges & & & \\
\hline \multirow[t]{2}{*}{ Parameters } & G1 & $\mathrm{G} 2$ & G3 & $P$-value \\
\hline & $(N=89)$ & $(\mathrm{N}=33)$ & $(N=52)$ & \\
\hline Age (years) & $39(23-63)$ & $34(25-52)$ & $33(21-66)$ & 0.014 \\
\hline ALT $(\times \operatorname{ULN})$ & $\begin{array}{l}0.48(0.24- \\
0.92)\end{array}$ & $0.82(0.34-1.88)$ & $0.53(0.24-1.66)$ & $<0.0001$ \\
\hline AST $(\times \cup L N)$ & $0.61(0.4-1.58)$ & $0.75(0.53-1.43)$ & $0.65(0.38-1.98)$ & $<0.0001$ \\
\hline qHBsAg $(I U / m L)$ & $\begin{array}{l}2.4(-0.71- \\
4.63)\end{array}$ & $3.5(0.77-4.76)$ & $3.16(1.94-4.8)$ & $<0.0001$ \\
\hline HBV DNA (IU/mL) & 2.00 (ND-3.24) & $3.79(1.08-6.24)$ & 3.29 (ND-4.12) & $<0.0001$ \\
\hline HBV DNA/qHBsAg ratio & 0.81 & 1.01 & 1 & 0.006 \\
\hline Alkaline phosphatase (U/L) & $73(36-145)$ & $72(50-124)$ & $76.5(39-135)$ & 0.69 \\
\hline $\begin{array}{l}\text { Gamma glutamyl transferase } \\
(\mathrm{U} / \mathrm{L})\end{array}$ & $18(6-65)$ & $25(14-60)$ & $18(7-77)$ & 0.001 \\
\hline Total bilirubin $(\mu \mathrm{mol} / \mathrm{L})$ & $12(3.7-25)$ & $13(7-27)$ & $12.7(7.5-42)$ & 0.001 \\
\hline Prothrombin time (\%) & $97(71-100)$ & $95(75-100)$ & $97(61-100)$ & 0.49 \\
\hline \multirow[t]{2}{*}{ Leukocytes (/mm3) } & 6420 & 6420 & 6470 & 0.73 \\
\hline & $(3990-16400)$ & $(4070-9490)$ & $(3860-10050)$ & \\
\hline Hemoglobin (g/dL) & $14.9(11-18)$ & $15.3(11.1-17.3)$ & $14.8(10.2-18.4)$ & 0.38 \\
\hline \multirow[t]{2}{*}{ Platelets (/mm3) } & 213000 & 219000 & 226000 & 0.73 \\
\hline & $\begin{array}{l}(117000- \\
43500)\end{array}$ & $\begin{array}{l}(113000- \\
345000)\end{array}$ & $\begin{array}{l}(129000- \\
241000)\end{array}$ & \\
\hline
\end{tabular}

G, group; G1, inactive carriers ; G2, HBeAg negative chronic hepatitis B patients; G3, patients with indeterminate status; ALT, Alanine aminotransferase; ULN, upper limit of normal; AST, Aspartate aminotransferase; qHBsAg, quantitative hepatitis B surface antigen; HBV DNA, hepatitis B virus deoxyribonucleic acid

\section{Figures}




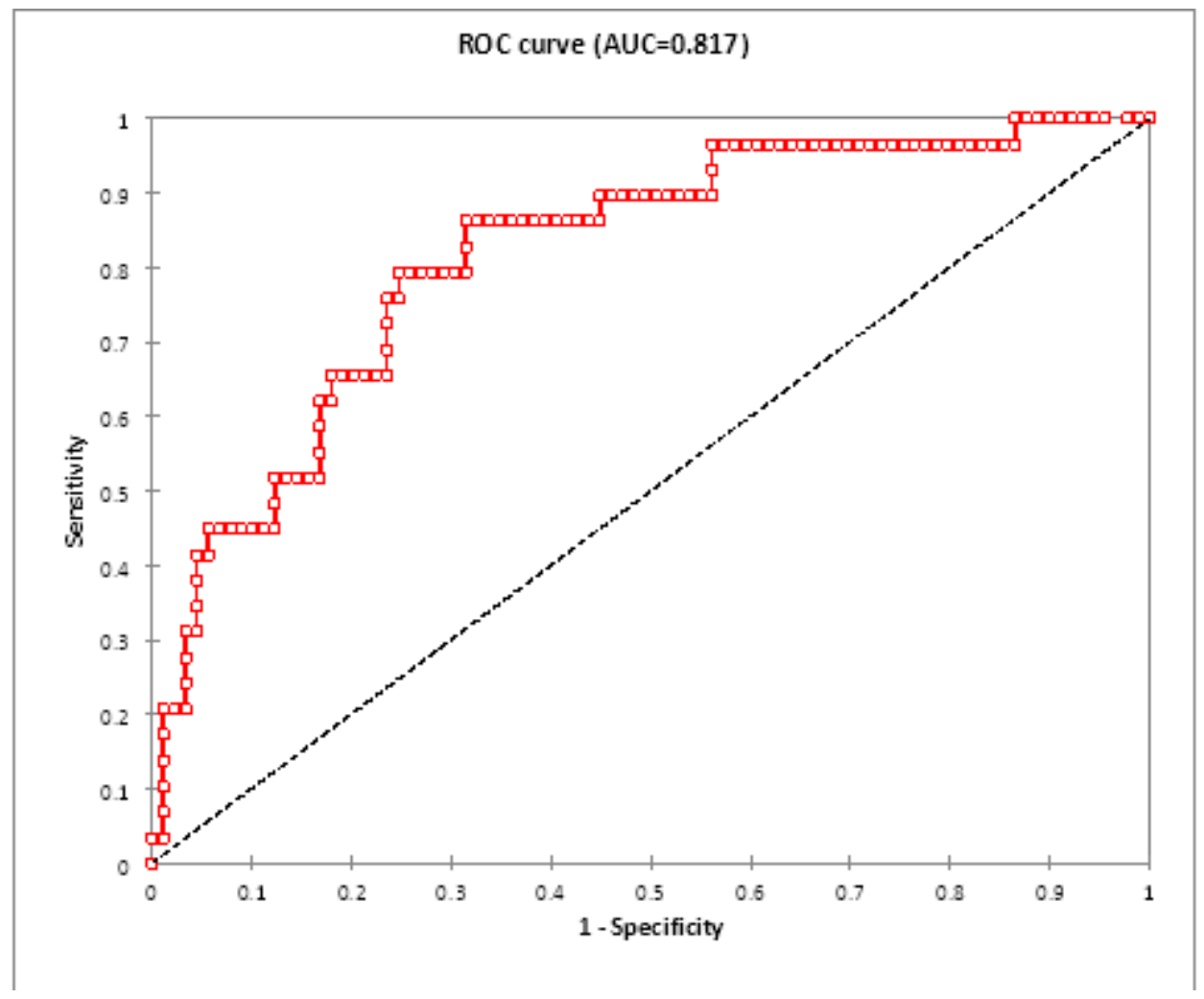

\section{Figure 1}

ROC curve analysis of clinical usefulness of qHBsAg

The diagnostic performance of qHBsAg serum levels was evaluated by receiver operating characteristic (ROC) curve in order to establish a cut-off value of qHBsAg allowing the identification, at the first visit (M0), of the clinical phase of chronic infection with negative HBeAg (chronic hepatitis B or inactive carriage). The qHBsAg cut off to discriminate was selected considering the highest sensitivity + specificity sum. Only G1 and G2 patients were included in the analysis, as having a well-defined status at the end of follow-up. The area under the receiver operating characteristic (AUROC) of qHBsAg to identify $\mathrm{CHB}$ in the overall cohort was 0.817 